\title{
Salinity and water effect on electrical properties of fragile clayey sandstone
}

\author{
Mohamed Mahmoud Gomaa ${ }^{1}$
}

Received: 4 April 2019 / Accepted: 30 March 2020 / Published online: 21 April 2020

(c) The Author(s) 2020

\begin{abstract}
There are enormous variations in the electrical characteristics of rocks and minerals according to many factors. Electrical measurements were taken to define the weight of these variations. Water saturation effect (partially and fully) on electrical characteristics of loose clayey sandstone samples was studied. Measurements were taken at room temperature $\left(\sim 19^{\circ} \mathrm{C}\right)$ and a frequency range of $(0.0005 \mathrm{~Hz}-100 \mathrm{kHz})$. Changes in water content are the only factor that controls changes in electrical properties. Change in frequency with water content is an important factor for electrical properties. At relatively low frequencies and low saturations, an interface between grains (charge accumulation at grain surfaces and bound water) is the dominating factor. Also, the bulk material properties at high frequency and full saturations are the controlling factors. At moderate saturations, there are surface charge displacement and exchange of excess ions between grains. For high saturations, due to existence of high mobilities of excess ions, the diffusion or membrane polarization is the main controlling mechanisms. The water used in the sample is $4 \mathrm{~g}$ of $\mathrm{NaCl} / 100 \mathrm{~g}$ of distilled water. The electrical conductivity of the samples increases gradually with the addition of saline water. With an increase in frequency, variations of conductivity may be negligible.
\end{abstract}

Keywords Electrical conductivity $\cdot$ Dielectric constant $\cdot$ Complex impedance $\cdot$ Saturation $\cdot$ Loose clayey sandstone $\cdot$ Frequency domain

\section{Introduction}

Semiconductor materials may have conductivity values of range of $10^{-4}-10^{-9} \mathrm{~S} / \mathrm{cm}$. Dielectrics have conductivities less than $10^{-9} \mathrm{~S} / \mathrm{cm}$. There is no precise boundary between conductors or insulators. Charge carriers (electrons) in semiconductors are responsible for electrical conductivity. In dielectrics or insulator materials, charge carriers cannot move over large distances because the conducting paths are generally broken. Metals and semiconductors have the same charge carriers for electrical conductivity (electrons). Activation energy required for electrons is the basic difference between these two material types. In metals, activation energy needed is nearly zero, while in semiconductors, it is up to several electron volts. Semiconductors are insulators (nearly) at low temperatures. Charge carriers are not free to move over large distances, especially in heterogeneous

Mohamed Mahmoud Gomaa

mmmsgomaa@yahoo.com

1 Geophysical Sciences Department, National Research Centre, El-Behoos St., Dokki, Cairo, Egypt geological mixtures. Generally, dielectrics may have some weak bonded charged particles. When an external field is applied, these weak charge bonds can be linked to form an electrical current. Ore-bearing rocks or ore minerals show semiconductor properties. Semiconductors conductivity is very sensitive to minor changes in chemical composition and accordingly to water quantity. Composite materials of ore minerals are supposed to have good sources of charge carriers. If charge carriers are near the conduction band, then the transfer of electrons requires only a small energy (e.g., increase in frequency or temperature). Electrical conduction for semiconductors may be by electrons only. This is dependent on the distance between energy levels.

There is a very wide range of conductivity values for rocks ( 20 orders of magnitude). This is dependent on the constituents of the minerals constituting the rock mixture. However, when the water is present in a rock sample, it shows a huge dominant effect on electrical characteristics of sedimentary rocks. Also, the existence of salinity may add another dominant effect to the electrical properties. Impurities at samples may lead to huge electrical properties variations, especially for saturated composites, in addition to the 
humidity saturation or effect (Leroy and Revil 2004; Mendelson and Cohen 1982; Gomaa and Kassab 2016; Kassab et al. 2017).

The A.C. electrical characteristics of partially and fully saturated loose clayey sandstone specimens, at frequency range of $0.0005 \mathrm{~Hz}-100 \mathrm{kHz}$, were studied. Electrical properties change from one sample to another because there are many texture differences between these samples (Gomaa et al. 2015a, b; Gomaa and Abou El-Anwar 2015), with the existence of more conduction paths from the saline water. Every sample has a separate structure and connections (texture). To eliminate the changes in texture and to remove any other differences (grain size, permeability, grain shape, structure, concentration, etc.), electrical measurements were taken only on one sample with different water saturations (from partial to saturated). That material is an example of a mixture of multicomponent system (sand, clay, saline water and air). The main concentration of the used sample is sand $(\sim 70 \%)$ and clay $(\sim 30 \%)$. Grain size of sand in sample is in the order from 0.09 to $1.7 \mathrm{~mm}$, and grain size of clay in sample is in the order of $\sim 60 \mu \mathrm{m}$.

In this article, an attempt was made to interpret the effect of saline water on electrical characteristics of that loose clayey sandstone specimen. Clayey sandstone specimens are good dielectrics at room temperatures with a conductivity of the order from $\sim 10^{-4}$ to $\sim 10^{-6} \mathrm{~S} / \mathrm{m}$, when it is dry (Gomaa 2009; Shaltout et al. 2012; Abou El-Anwar and Gomaa 2013, 2016). The presence of some polarization processes with the surface conduction mechanisms on grain surfaces motivates high values of dielectric constant (Chelidze et al. 1999; Ruffet et al. 1991a, b). With applying an electric field, the ions polarize around the rock grains, giving rise to large dipoles and large dielectric constants (Garrouch and Sharma 1994; Minor et al. 1998; Shilov et al. 2001). As the frequency increases, ions could not follow the applied electrical field and accordingly have less time to polarize and contribute more to the conductivity, since they are more in phase with the applied electric field (Gomaa and Abou El-Anwar 2017; Cole and Cole 1941).

Existence of water at rock mixtures can be classified from electrical point of view as: adsorbed water, free water and capillary water (Mitchell 1992; Saarenketo 1998). The presence of minute water causes the increase in electrical values. The first additions of water form some separated clusters from each other, at the beginning (very small saturations). With more additions of water, these separated clusters of water become connected and coat most of grain surfaces (Gomaa 2008, 2013). Salinity of water adds more ions and electrons to the conduction process in the sample. For the partial saturation cases, water molecules (at the adsorbed layers) form vigorous links with surface grains and a certain polarization mechanism may be arise (orientation polarization or reversible hopping, Glover et al. (1994a). For the higher saturation cases, polarization may be by dipole (molecules), orientation polarization or charge transfer through ions or protons (in Helmholtz or diffuse double layer). The surface proton conduction mechanism may be along hydroxylic groups or chains (Saarenketo 1998). The hydrogen ions may effectively conduct through water molecules of hydrogen bonds at adsorbed layers (Pride 1994).

The process of polarization due to the presence of water multilayers is much more effective than the orientation polarization (Leroy and Revil 2004). At low saturations, a local high charge density is present at grain surfaces, with a strong electrostatic field. These localized charges enhance water dissociation to provide charge carriers (protons) to make hopping transport (Garrouch 2001). The transport of charges occurs when $\left[\mathrm{H}_{3} \mathrm{O}\right]^{+}$releases a proton to the adjacent molecule of water, while another proton is released after that and so on (Garcia-Belmonte et al. 2003). At relatively high saturations, isolated water clusters are connected, and water conduction occurs along with protonic transport (Dukhin 1971; Pride 1994; Glover et al. 1994a, b).

The specific surface conduction, at pure water, connected to the transfer of proton is $\sim 2.4 \times 10^{-9} \mathrm{~S}$ (Revil and Glover 1998). Surface migration and diffusion are often greatly distinguished than the mixture component polarization. Revil and Glover (1998) display that contribution of an electrical diffuse layer to surface conductivity is neglected (silica and alumino-silicates). The main contribution is related to surface conductivity that resulted from counterions located at the Stern layer. Surface mobility, at the Stern layer, is nearly ten times smaller than the bulk mobility. The independence of salinity is another contribution from the direct proton transfer, on the mineral surface.

At relative low frequencies, the dielectric distributions resulted from polarization of counterions around particles (Schwarz 1962). The displacement of counterions gives abnormal dielectric constant. Abnormal dielectric constant related to polarization of electrical double layer at grain interface was discussed by Chelidze and Guéguen (1999). Application of an electric domain leads to migration and diffusion of charges and the existence of isolated clusters with excess of negative and positive charges (on different sides of grains). The large low-frequency polarization takes into account the heterogeneity in electrical charge distribution on grain interfaces (Chelidze and Guéguen 1999). In this model, relaxation time depends on charges cluster size on mineral surfaces rather than on particles grain size. The existence of excess or deficit produces ions to gather together and increase at interfaces, which are disjointed with surface (Wong 1979, 1987; Mehaute and Crepy 1983).

The dielectric effect interaction between water and rock (rock surface) was discussed at many studies (Knight and Nur 1987). They show that electrical characteristics increase with saturation increase. A critical saturation point may exist for saturated samples. Below that critical saturation, the resistivity 
Fig. 1 Change in dielectric constant with frequency at different saturation levels of saline water $(4 \mathrm{~g} / 100 \mathrm{~g}$ of $\mathrm{NaCl})$ [(1) diamond, (2) square, (3) triangle, (4) circle, (5) inverted triangle, (6) times symbol, (7) star symbol, (8) asterisk, (9) oplus symbol, (10) open square with times symbol]

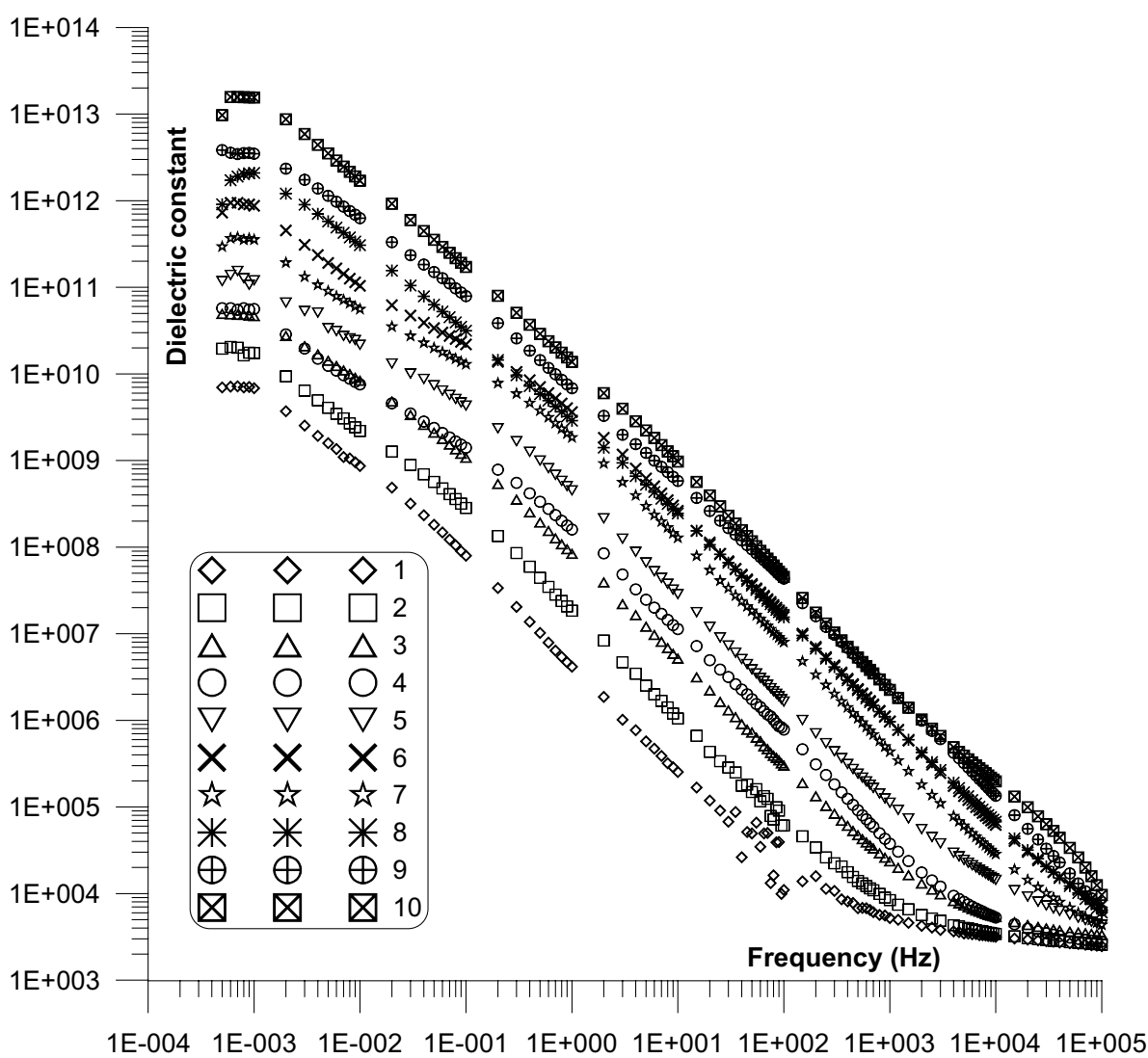

decreases gradually with saturation, and above it, the resistivity decrease slower. Power law is controlled by permittivity $(\varepsilon)$ as a function of frequency $(w)$ which is due to randomness of the grains and constituents within the samples (Jonscher 1999; Gomaa et al. 2018).

\section{Experimental procedures}

Electrical properties measurements were taken on a thin diskshaped loose clayey sandstone of thickness $10 \mathrm{~mm}$ and diameter $37 \mathrm{~mm}$.

Non-polarizing $\mathrm{Cu} / \mathrm{CuSO}_{4}$ gel electrodes were used at measurements (Gomaa and Alikaj 2009; Alikaj 1989). The electrode impedance was very small within the used frequency range.

Data were collected in the frequency range from $0.0005 \mathrm{~Hz}$ to $100 \mathrm{kHz}$ using a Hioki 3522-50 LCR Hitester Impedance Analyzer connected to the non-polarizing electrodes. A voltage of $1 \mathrm{~V}$ was applied.

The measured electrical properties parameters are the parallel capacitance and conductance $C_{\mathrm{p}}(\mathrm{F})$ and $G_{\mathrm{p}}(\mathrm{S})$ and the series impedance $Z$ at different frequencies. The maximum error of instrument is of the order of $7 \%$. The complex relative dielectric constant is $\varepsilon^{*}=\varepsilon^{\prime}-i \varepsilon^{\prime \prime}$.
The real part of the complex relative dielectric constant is $\varepsilon^{\prime}=C_{\mathrm{p}} d / \varepsilon_{0} A$, and the imaginary part is $\varepsilon^{\prime \prime}=G_{\mathrm{p}} d / w \varepsilon_{0} A$, where $A$ is the cross-sectional area of the sample $\left(\mathrm{m}^{2}\right)$, $d$ is its thickness $(\mathrm{m}), \varepsilon_{0}$ is the permittivity of free space $\left(8.85 \times 10^{-12} \mathrm{~F} / \mathrm{m}\right)$, and $w$ is the angular frequency. The conductivity and dielectric constant equations are $\sigma=d G_{\mathrm{p}} / A$ $(\mathrm{S} / \mathrm{m}), \varepsilon^{\prime}=C_{\mathrm{p}} / C_{0}, C_{0}=(A / d) \varepsilon_{0}(\mathrm{~F})$.

Sample weight dry was measured and at full saturation, by putting it in pressure vessel, then evacuating the vessel from air, allowing distilled water to flow into the vessel. Subsequent measurements with the determination of weight were made while the sample was let to dry. The saturation levels were calculated as

$W_{\mathrm{S}}=\left(\frac{S_{\text {wet }}-S_{\text {dry }}}{S_{\text {dry }}}\right) \times 100$

where $W_{\mathrm{S}}$ denotes water saturation $\% ; S_{\text {wet }}$ wet sample weight; and $S_{\text {dry }}$ dry sample weight.

The porosity $\phi$ of the sample $(\sim 13 \%)$ was calculated by

$\phi=\frac{\left(S_{\mathrm{sat}}-S_{\mathrm{dry}}\right)}{\rho_{\mathrm{w}} \times V} \times 100$ 
Fig. 2 Change in conductivity with frequency at different saturation levels of saline water $(4 \mathrm{~g} / 100 \mathrm{~g}$ of $\mathrm{NaCl})[(1)$ diamond, (2) square, (3) triangle, (4) circle, (5) inverted triangle, (6) times symbol, (7) star symbol, (8) asterisk, (9) oplus symbol, (10) open square with times symbol]

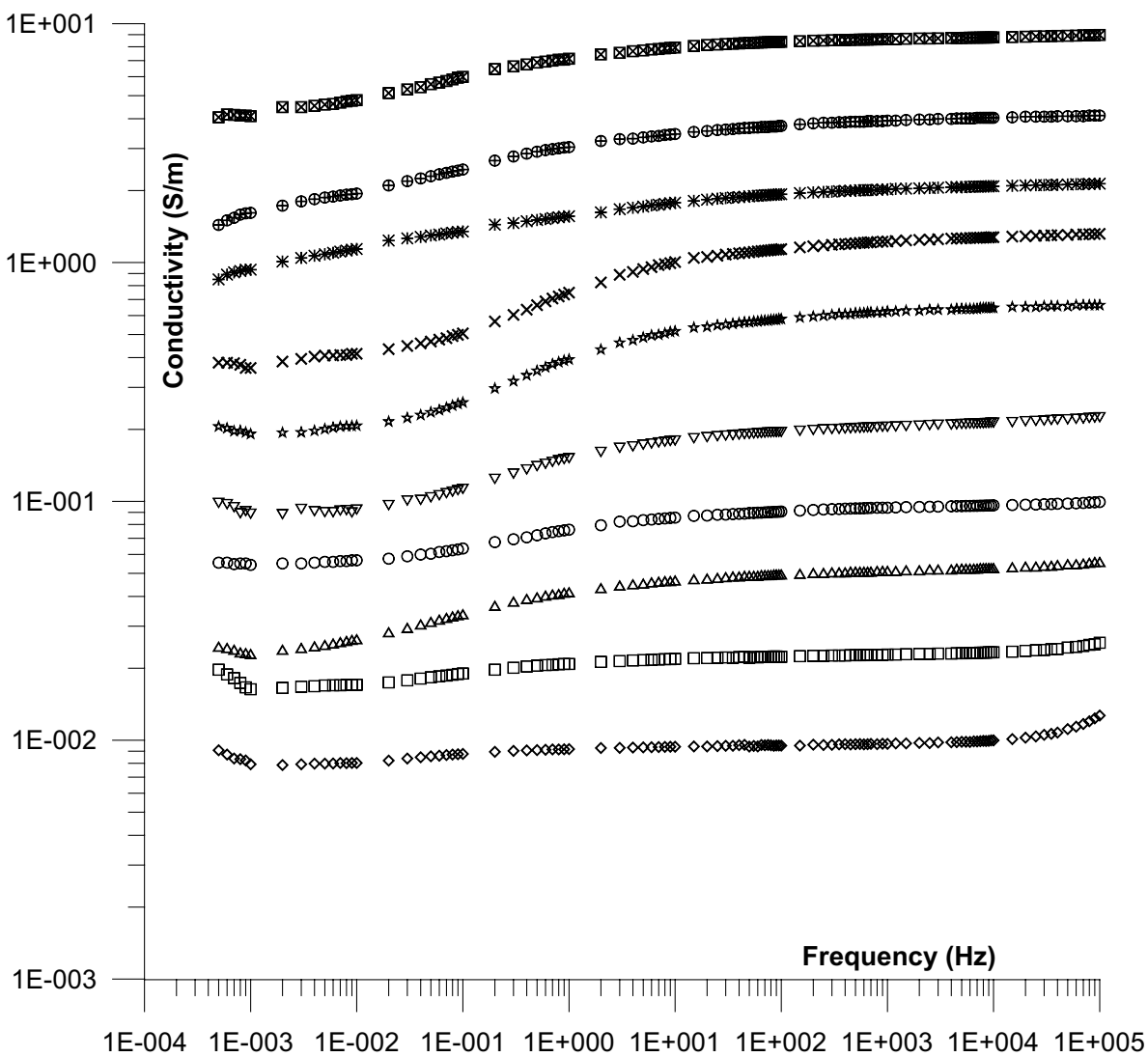

where $S_{\text {sat }}=$ saturated sample weight, $\rho_{\mathrm{w}}=$ water density $(\sim 1)$, and $V$ is the sample volume.

\section{Interpretation and discussions}

In rocks containing saline liquids, the dominant conduction comes from saline liquids, while the other rock texture (i.e., liquid or grains) may be negligible compared to it. At normal temperatures, when there are very rich disseminated ores, the rock texture conductivity cannot be negligible. Conversely, at very high temperatures, the conductivity of the semiconductor of minerals has the dominant effect. Liquids contribute to electrical conduction by their paths between pore spaces. Saline liquids have more conduction energy than usual liquids because there are more free charges from the saline itself. Voids between grains determine the shape of electric paths and accordingly their interface interaction with the solid grains.

The existence of disconnected links of semiconductor or insulator in the sample leads to polarized space charge at the ends of the semiconductors. This is usually present at partial saturations, while, for full saturations, polarization is not present at continuous conductor links. Charge carriers may move over a large distance through sample under the effect electric fields. The polarization of space charges takes place when charge carriers are obstructed. Charge carriers are trapped at the ends of grain (or cluster) interfaces, or when these charges are not able to be discharged freely, or when it is replaced at electrodes. The accumulation of charge carriers increases the permittivity or dielectric constant of samples. At low frequency, charges have enough time to gather together at interfaces of the conducting clusters, and accordingly, dielectric constant increases. At relatively high frequency, these charge carriers do not possess enough time to gather together at these interfaces of the conducting clusters, and accordingly, dielectric constant decreases.

The dielectric constant and conductivity increase with increase in relative saturation level. Figure 1 shows the change in dielectric constant with frequency at different saturation levels of saline water $(4 \mathrm{~g} / 100 \mathrm{~g}$ of $\mathrm{NaCl})$. Figure 2 shows the change in conductivity with frequency at different saturation levels of saline water $(4 \mathrm{~g} / 100 \mathrm{~g}$ of $\mathrm{NaCl}$ ). At first partial saturation case, there are some isolated clusters of water around grains and the pores are 
Fig. 3 Variation of complex resistivity plane as a function of frequency at different saturation levels of saline water $(4 \mathrm{~g} / 100 \mathrm{~g}$ of $\mathrm{NaCl}$ ) [(1) diamond, (2) square, (3) triangle, (4) circle, (5) inverted triangle, (6) times symbol, (7) star symbol, (8) asterisk, (9) oplus symbol, (10) open square with times symbol]

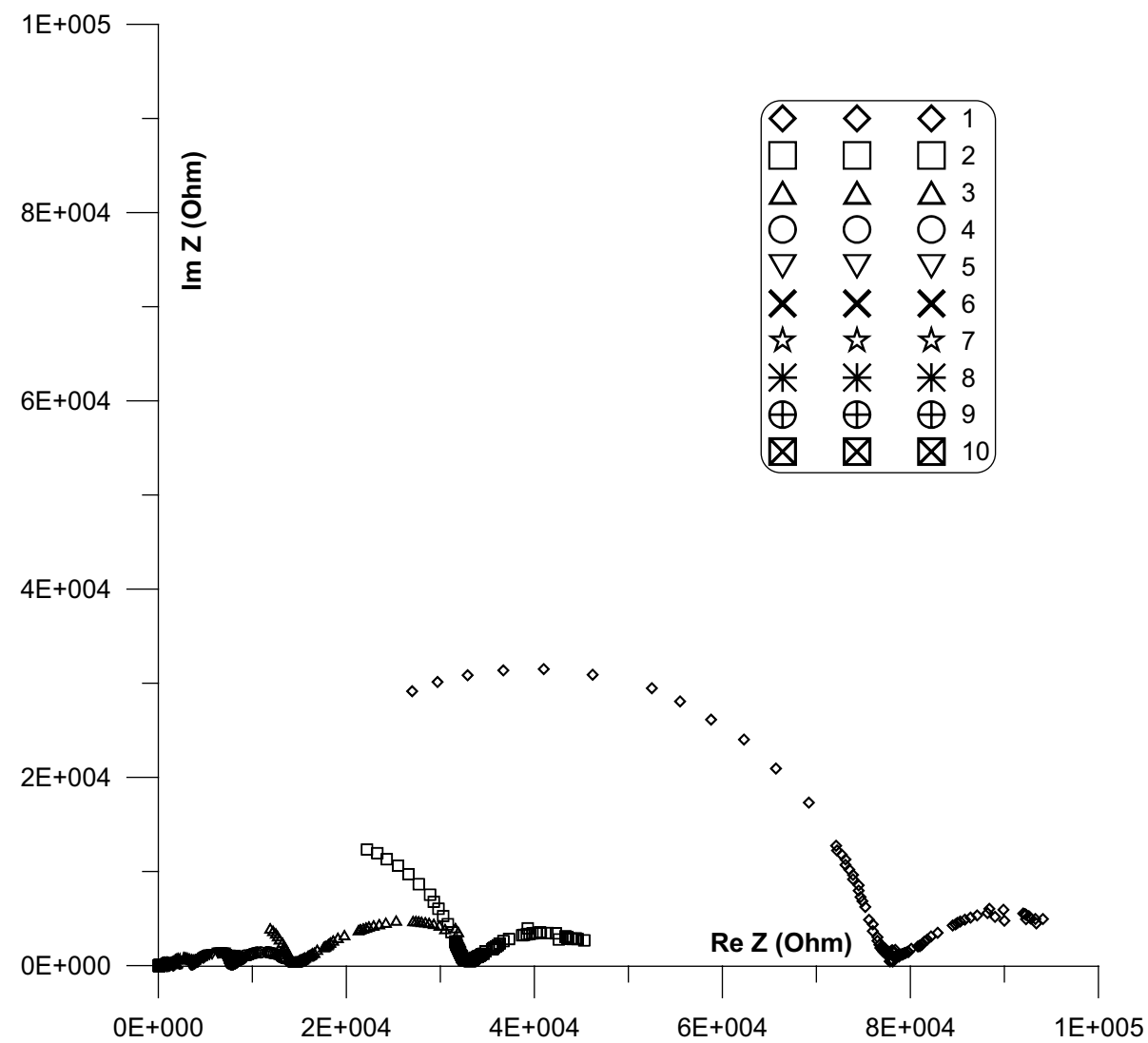

partially filled with air and/or water. With increase in the saturation of saline water, the adsorbed water forms some monolayers of water throughout grains which are completely bound to grain surfaces and cannot participate to the conduction current (contribute only to the diffusion current). This adsorbed water properties are totally different from the bulk water (Hoekstra and Doyle 1971; Knight and Endres 1990). With more increase in saturation of saline water and at higher saturations, the adsorbed water makes connected clusters of water. Due to increase in saline water saturation, the adsorbed water coats, completely, the grain surfaces and the small isolated clusters begin to contact with each other, forming small islands of water between grains. At the beginning, these disconnected islands are still isolated from each other and the inner water monolayers are strongly bonded to the surface (Glover et al. 1994a). Lately, after the saturation concentration increases, the isolated clusters become gradually connected with continuous fluid films that finally are connected between the two electrodes.

Dielectric constant values (Fig. 1) at low frequency $(0.0005 \mathrm{~Hz})$ vary from $10^{10}$ for low saturated loose clayey sandstone to $2 \times 10^{13}$ for full saline water saturation, while the values at high-frequency range $\left(10^{5} \mathrm{~Hz}\right)$ from $2 \times 10^{3}$ for low saline water saturation of loose clayey sandstone to $10^{4}$ for full saline water saturation. The ore clay minerals in the samples $\left(\mathrm{Fe}_{2} \mathrm{O}_{3}, \mathrm{MgO}, \mathrm{Na}_{2} \mathrm{O}, \mathrm{TiO}_{2}, \mathrm{Cu}, \mathrm{Mn}\right.$ and $\left.\mathrm{Zn}\right)$ lead to high abnormal dielectric constant values. These ore clay mineral chains in the samples are disconnected by $\mathrm{SiO}_{2}$. At relatively low frequencies, a dielectric constant of samples is related to the interface between grains at the dead ends of the conducting chains. This interface dielectric constant is much higher than an intrinsic bulk dielectric constant of the sample. Also, the dielectric constants increase monotonically with a further increase in the degree of saline water saturation. Electrical properties are affected by salinity distribution at grain surfaces and show a great dependence on the cluster interconnection (chemical interaction or surface activity). These remarkable differences and changes in the texture connections of the samples will, without doubt, result in different amounts of electric properties. More clearly, the saline water saturation in the samples has a much higher dielectric constant and conductivity at relatively low frequencies due to free ions at saline water combined with conducting ore clay minerals in the samples $\left(\mathrm{Fe}_{2} \mathrm{O}_{3}, \mathrm{MgO}\right.$, $\mathrm{Na}_{2} \mathrm{O}, \mathrm{TiO}_{2}, \mathrm{Cu}$ and $\mathrm{Mn}$ ); charges move freely at the liquid. The connection between the different discontinuous conducting clusters within the whole composite, without doubt, decreases the whole surface area of the cluster in addition to overall charge transportation capability. Generally, above the critical saturation, the broken clusters begin to connect leading to the mutual decrease in the dielectric constant. At

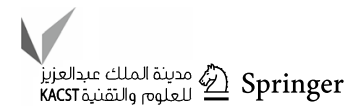



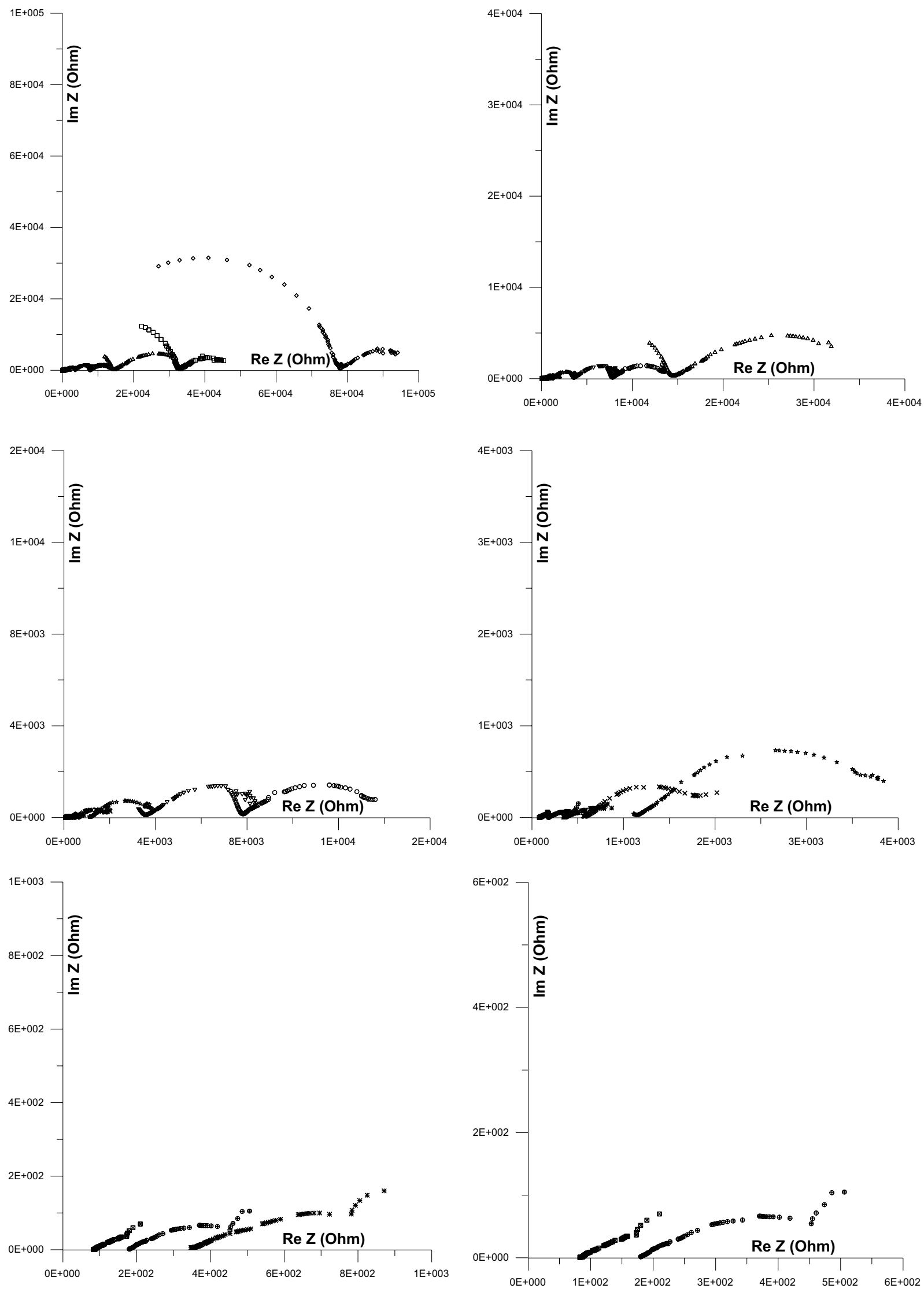
4Fig. 4 Variation details of complex resistivity plane as a function of frequency at different saturation levels of saline water $(4 \mathrm{~g} / 100 \mathrm{~g}$ of $\mathrm{NaCl}$ ) [(1) diamond, (2) square, (3) triangle, (4) circle, (5) inverted triangle, (6) times symbol, (7) star symbol, (8) asterisk, (9) oplus symbol, (10) open square with times symbol]

the present case, the salinity only increases and the clusters do not increase. Accordingly, dielectric constant increases monotonically due to increase in charges of the saline water. In the present case, the clusters of the saturated clayey sandstone sample are not completely connected and accordingly dielectric constant is high even with an increase in sample salinity.

At low frequency, the dielectric constant has a powerlaw dependence ( $\varepsilon \propto f^{-\alpha}$, Fig. 1), which is not changed at a certain frequency $(100 \mathrm{~Hz})$. At high frequency (above $100 \mathrm{~Hz}$ ), the power-law dependence on dielectric constant may be present with a different value of $\alpha$ exponent. That high-frequency region begins at nearly $100 \mathrm{~Hz}$ for low saturation, while it takes the whole frequency range at higher saline water saturations. For very high-salinesaturation samples, there is (nearly) only one region of dispersion of dielectric constant in the whole frequency range. The frequency separating regions 1 and 2 (Fig. 1) increases with increase in water saturation above a critical value (Wilkinson et al. 1983). The physical mechanisms supposed for relatively low saturations can be either the orientation polarization or the transfer of charges (protons of a diffuse double layer or ions in the Helmholtz) along with hydroxylic bonds or groups (surface charge transfer) at Stern layer (Schwan et al. 1962; Schwarz 1962). There is a relaxation time distribution due to existence of different polarization discontinuous clusters of different dimensions on grains surfaces (Dukhin 1971; Gomaa and Elsayed 2009; Gomaa et al. 2009).

Charges either diffuse along with the discontinuous clusters (of saline water) coating the grains or diffuse through the bulk of the conducting grains of the specimen. When charge surfaces contacts with liquid water, electrolytes are originated and the electrical field associated with ionic deviation causes electrical conduction (Knight and Nur 1987).

In the conductivity curves (Fig. 2), two adjacent regions are found with power law $\sigma \propto f^{\alpha}$ of conductivity, with frequency, with different slopes. In the first region, at relative low frequencies, for low and high saline saturations, there is slight dispersion of the conductivity. That region ends at nearly $1 \mathrm{~Hz}$ for most of saturated samples. For very high saturations (above $1 \mathrm{~Hz}$ ), no frequency dispersion is present at the whole frequency range. Results of conductivity, at low frequency $(0.0005 \mathrm{~Hz})$, vary from $9 \times 10^{-3} \mathrm{~S} / \mathrm{m}$ for low saturated clayey sandstone samples to $4 \mathrm{~S} / \mathrm{m}$, for high saline water saturation. Also, results of the conductivity for high frequency $\left(10^{5} \mathrm{~Hz}\right)$ range from $2 \times 10^{-2} \mathrm{~S} / \mathrm{m}$ for low saturated clayey sandstone samples to $10 \mathrm{~S} / \mathrm{m}$ for high saline water saturation (this is nearly the saline water conductivity). Low-frequency zone is characterized by existence of continuous links of water with clay minerals between the electrodes, thus causing nearly constant conductivity with frequency. Even with the successive additions of saline water concentration, the conductivity values change about three decades, while with the successive increase in frequency at the whole frequency extension, the maximum conductivity values change about half decade. The continuous conduction paths of saline water between the grains increase with increasing saline water content; thus, the conductivity increases. The samples that have the same concentrations of water, clay and sand may not have the same behavior of electrical properties due to change in the texture from one sample to another (Efros and Shklovskii 1976; Knight 1983; Olhoeft 1985; Sen 1989; Levitskaya and Sternberg 2000).

Figures 3 and 4 show the complex resistivity plane representation of the sample at different saturation levels of saline water $(4 \mathrm{~g} / 100 \mathrm{~g}$ of $\mathrm{NaCl})$. The data are exhibited in two Figs. 3 and 4 due to a wide range of values on a linear scale. Figure 3 shows all the saturations in one curve, and Fig. 4 shows the details of the other ten saturations. For low-saline-water-saturation case, nearly two incomplete semicircles can be identified for seven saline saturations. As the saline water saturation increases, the first low-frequency dampened semicircle is getting bigger and the second highfrequency dampened semicircle is getting smaller. This is a representation of the decrease in the resistance. The characteristic frequency that separates the two dampened semicircles increases with the addition of saline water. Also, the depression of the dampened semicircles increases with an increase in the saline water saturation, i.e., increase in the conductivity (Grant 1958). Such dominance of the real resistivity over the imaginary resistivity, due to increase in saline water saturation, is representative to increase in continuous conductor paths in the sample. The low-frequency part of the dampened semicircle is a representation of the resistivity that controls the diffusion in addition to electrode polarization, which is dependent on saline water saturation (Macdonald 1974; Roberts and Lin 1997; Knight and Nur 1987). Frequency domain of electrode effect extends to higher frequencies with the addition of saline water (Knight and Nur 1987).

\section{Conclusion}

Effects of saline water $(4 \mathrm{~g} / 100 \mathrm{~g}$ of $\mathrm{NaCl})$ saturations on the electrical conductivity and dielectric constant, as a function of frequency $(0.0005 \mathrm{~Hz}-100 \mathrm{kHz})$, for partially and fully saturated clayey sandstone samples are investigated.

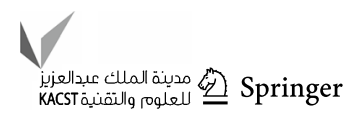


Experimental results show that the electrical characteristics of the sample are strongly affected by the addition of saline water. At low saline water saturations, the general increase in electrical properties values is relatively small. At relatively higher saline water saturations, the general increase in electrical properties values becomes higher because the ore mineral charges increase. The ore clay minerals in the samples $\left(\mathrm{Fe}_{2} \mathrm{O}_{3}, \mathrm{MgO}, \mathrm{Na}_{2} \mathrm{O}, \mathrm{TiO}_{2}, \mathrm{Cu}, \mathrm{Mn}\right.$ and $\mathrm{Zn}$ ) lead to high abnormal dielectric constant values. With an increase in frequency, dielectric constant values change from frequency dependent to frequency independent. At relatively low frequencies and low saturations, charge accumulation is the dominating factor. Bulk properties at full saturation and high frequency are the dominating factors. Bound water orientation polarization, at low saturations, is the controlling mechanism, at low frequency. At moderate and high saturations, there is surface charge displacement and exchange of excess ions between grains and the diffusion or membrane polarization are the controlling mechanisms. Permittivity measurements are affected by discontinuous semiconductor clusters on grain surfaces for relatively low saline water saturations. At relative low saline water saturations, conductivity is developed from electronic hopping conduction, while at relative high saturations the conductivity is developed from electrolytic and proton conduction from the ore minerals of the clay.

\section{Compliance with ethical standards}

Conflict of interest The authors have no conflict of interest to declare.

Open Access This article is licensed under a Creative Commons Attribution 4.0 International License, which permits use, sharing, adaptation, distribution and reproduction in any medium or format, as long as you give appropriate credit to the original author(s) and the source, provide a link to the Creative Commons licence, and indicate if changes were made. The images or other third party material in this article are included in the article's Creative Commons licence, unless indicated otherwise in a credit line to the material. If material is not included in the article's Creative Commons licence and your intended use is not permitted by statutory regulation or exceeds the permitted use, you will need to obtain permission directly from the copyright holder. To view a copy of this licence, visit http://creativecommons.org/licenses/by/4.0/.

\section{References}

Abou El-Anwar E, Gomaa MM (2013) Electrical properties and geochemistry of carbonate rocks from the Qasr El-Sagha formation, El-Faiyum, Egypt. Geophys Prospect 61:630-644

Abou El-Anwar E, Gomaa MM (2016) Electrical, mineralogical, geochemical and provenance of Cretaceous black shales, Red Sea Coast, Egypt. Egypt J Pet 25:323-332

Alikaj P (1989) The study of spectral characteristics of induced polarization in search for high grade sulphide ore bodies. $\mathrm{PhD}$ thesis, Polytechnic University of Tirana, Albania
Chelidze T, Guéguen Y (1999) Electrical spectroscopy of porous rocks: a review-I. Theoretical models. Geophys J Int 137:1-15

Chelidze T, Guéguen Y, Ruffet C (1999) Electrical spectroscopy of porous rocks: a review-II. Experimental results and interpretation. Geophys J Int 137:16-34

Cole KS, Cole RH (1941) Dispersion and adsorption in dielectrics (I). J Chem Phys 137:341-351

Dukhin SS (1971) Dielectric properties of disperse systems. In: Matijevic E (ed) Surface and colloid science, vol 3. Wiley, New York, pp 83-166

Efros AL, Shklovskii BI (1976) Critical behaviour of conductivity and dielectric constant near the metal-non-metal transition threshold. Phys Status Solidi 137:475-489

Garcia-Belmonte G, Kytin T, Dittrich J (2003) Bisquert, Effect of humidity on the ac conductivity of nanoporous $\mathrm{TiO}_{2}$. J Appl Phys 94(8):5261-5264

Garrouch AA (2001) Effect of wettability and water saturation on the dielectric constant of hydrocarbons rocks. In: 41st Annual logging symposium (SPWLA), paper NN

Garrouch AA, Sharma MM (1994) The influence of clay content, salinity, stress and wettability on the dielectric properties of brine-saturated rocks: $10 \mathrm{~Hz}$ to $10 \mathrm{MHz}$. Geophysics 137:909-917

Glover PWJ, Meredith PG, Sammonds PR, Murrel SAF (1994a) Ionic surface electrical conductivity in sandstone. J Geophys Res 99(b11):21635-21650

Glover PWJ, Meredith PG, Sammonds PR, Murrel SAF (1994b) Measurements of complex electrical conductivity and fluid permeabilities in porous rocks at raised confining pressures. In: Rock mechanics in petroleum engineering, proceedings of the EUROROCK94, Balkema, Amsterdam, pp 29-36

Gomaa MM (2008) Relation between electric properties and water saturation for hematitic sandstone with frequency. Ann Geophys 51(5/6):801-811

Gomaa MM (2009) Saturation effect on electrical properties of hematitic sandstone in the audio frequency range using non-polarizing electrodes. Geophys Prospect 57:1091-1100

Gomaa MM (2013) Forward and inverse modeling of the electrical properties of magnetite intruded by magma, Egypt. Geophys J Int 194(3):1527-1540

Gomaa MM, Abou El-Anwar E (2015) Electrical and geochemical properties of tufa deposits as related to mineral composition in South Western Desert, Egypt. J Geophys Eng 12(3):292-302

Gomaa MM, Abou El-Anwar E (2017) Electrical, mineralogical, and geochemical properties of Um Gheig and Um Bogma Formations, Egypt. Carbonates Evaporites 1-14

Gomaa MM, Alikaj P (2009) Effect of electrode contact impedance on a. c. electrical properties of wet hematite sample. Mar Geophys Res 30(4):265-276

Gomaa MM, Elsayed RM (2009) Thermal effect of magma intrusion on electrical properties of magnetic rocks from Hamamat Sediments, NE Desert, Egypt. Geophys Prospect 57(1):141-149

Gomaa MM, Kassab M (2016) Pseudo random renormalization group forward and inverse modeling of the electrical properties of some carbonate rocks. J Appl Geophys 135:144-154

Gomaa MM, Shaltout A, Boshta M (2009) Electrical properties and mineralogical investigation of Egyptian iron ore deposits. Mater Chem Phys 114(1):313-318

Gomaa MM, Kassab M, El-Sayed NA (2015a) Study of petrographical and electrical properties of some Jurassic carbonate rocks, north Sinai, Egypt. Egypt J Pet 24:343-352

Gomaa MM, Kassab M, El-Sayed NA (2015b) Study of electrical properties and petrography for carbonate rocks in the Jurassic Formations: Sinai Peninsula, Egypt. Arab J Geosci 8(7):4627-4639 
Gomaa MM, Metwally H, Melegy A (2018) Effect of concentration of salts on electrical properties of sediments, Lake Quaroun, Fayium, Egypt. Carbonates Evaporites 1-9

Grant FA (1958) Use of complex conductivity in the representation of dielectric phenomena. J Appl Phys 29(1):76-80

Hoekstra P, Doyle WT (1971) Dielectric relaxation of surface adsorbed water. J Colloid Interface Sci 137:513-521

Jonscher AK (1999) Dielectric relaxation in solids. J Phys D Appl Phys 32:R57-R70

Kassab M, Gomaa MM, Lala A (2017) Relationships between electrical properties and petrography of El-Maghara sandstone formations, Egypt. NRIAG J Astron Geophys 6:162-173

Knight R (1983) The use of complex plane plots in studying the electrical response of rocks. J Geomagn Geoelectr 137:767-776

Knight RJ, Endres AL (1990) A new concept in modeling the dielectric response of sandstones: defining a wetted rock and bulk water system. Geophysics 55:586-594

Knight RJ, Nur A (1987) The dielectric constant of sandstones, $50 \mathrm{kHz}$ to $4 \mathrm{MHz}$. Geophysics 52:644-654

Leroy P, Revil A (2004) A triple layer model of the surface electrochemical properties of clay minerals. J Colloid Interface Sci 270(2):371-380

Levitskaya TM, Sternberg BK (2000) Application of lumped-circuit method to studying soils at frequencies from $1 \mathrm{kHz}$ to $1 \mathrm{GHz}$. Radio Sci 35(2):371-383

Macdonald JR (1974) Binary electrolyte small-signal frequency response. Electroanal Chem Interface Electrochem 53:1-55

Mehaute A, Crepy G (1983) Introduction to transfer and motion in fractal media; the geometry of kinetics. Solid State Ion 137:17-30

Mendelson KS, Cohen MH (1982) The effect of grain anisotropy on the electrical properties of sedimentary rocks. Geophysics 47(2):257-263

Minor M, Van Leeuwen HP, Lyklema J (1998) Low-frequency dielectric response of polystyrene latex dispersions. J Colloid Interface Sci 206(2):397-406

Mitchell JK (1992) Fundamentals of soil behaviour, 2nd edn. Wiley, New York, p 437

Olhoeft GR (1985) Low frequency electrical properties. Geophysics 137:2492-2503

Pride S (1994) Governing equations for the coupled electromagnetics and acoustics of porous media. Phys Rev B 50(1):15678-15696

Revil A, Glover PWJ (1998) Theory of ionic surface electrical conduction in porous media. Phys Rev B 55(3):1757-1773
Roberts J, Lin W (1997) Electrical properties of partially saturated Topopah Spring tuff: water distribution as a function of saturation. Water Resour Res 33:577-587

Ruffet C, Guéguen Y, Darot M (1991a) Rock conductivity and fractal nature of porosity. Terra Nova 137:265-275

Ruffet C, Guéguen Y, Darot M (1991b) Complex measurements and fractal nature of porosity. Geophysics 137:758-768

Saarenketo T (1998) Electrical properties of water in clay and silty soils. J Appl Geophys 40:73-88

Schwan HP, Schwarz G, Maczuk J, Pauly H (1962) On the low-frequency dielectric dispersion of colloidal particles in electrolyte solution. J Phys Chem 66:2626-2635

Schwarz G (1962) A theory of the low-frequency dielectric dispersion of colloidal particles in electrolyte solution. J Phys Chem 66:2636-2642

Sen PN (1989) Unified models of conductivity and membrane potential of porous media. Phys Rev B 137:9508-9517

Shaltout AA, Gomaa MM, Wahbe M (2012) Utilization of standardless analysis algorithms using WDXRF and XRD for Egyptian Iron Ores identification. X-Ray Spectrom 41:355-362

Shilov VN, Delgado AV, Gonzalez-Caballero F, Grosse C (2001) Thin double layer theory of the wide-frequency range dielectric dispersion of suspensions of non-conducting spherical particles including surface conductivity of the stagnant layer. Colloids Surf A 192:253-265

Wilkinson D, Langer JS, Sen PN (1983) Enhancement of the dielectric constant near a percolation threshold. Phys Rev B 28(2): 1081-1087

Wong J (1979) An electrochemical model of the induced-polarization phenomenon in disseminated sulfide ores. Geophysics 44:1245-1265

Wong PZ (1987) Fractal surfaces in porous media. In Bahavar JP, Koplik J, Winkler KW (eds) Physics and Chemistry of Porous Media, vol 137, American Institute of Physics, 154, pp 304-318

Publisher's Note Springer Nature remains neutral with regard to jurisdictional claims in published maps and institutional affiliations. 